\title{
Tomographic evaluation of the temporomandibular joint in malocclusion subjects: condylar morphology and position
}

\section{Luciana Fonseca MERIGUE(a) Ana Cláudia de Castro Ferreira CONTI(b) \\ Paula Vanessa Pedron \\ OLTRAMARI-NAVARRO(a) \\ Ricardo de Lima NAVARRO(c) \\ Marcio Rodrigues de ALMEIDA(a)}

(a) Universidade do Norte do Paraná UNOPAR, Faculdade de Odontologia, Department of Orthodontic, Londrina, PR, Brazil.

(b) Universidade do Sagrado Coração - USC, Faculdade de Odontologia, Department of Orthodontics, Bauru, SP, Brazil.

(c) Universidade Estadual de Maringá - UEM, Department of Dentistry, Area of Oral and Maxillofacial Surgery, Maringá, PR, Brazil.

Declaration of Interests: The authors certify that they have no commercial or associative interest that represents a conflict of interest in connection with the manuscript.

\section{Corresponding Author:}

Ana Cláudia de Castro Ferreira Conti E-mail: accfconti@uol.com.br

DOI: 10.1590/1807-3107BOR-2016.vol30.0017

Submitted: May 28, 2015

Accepted for publication: Ago 26, 2015

Last revision: Sep 29, 2015

\begin{abstract}
The aim of this study was to investigate condyle concentricity and morphology, and their association with Class I and II malocclusions (Angle). The sample consisted of 49 individuals of both genders, between 11 and 35 years old, divided into two groups, G1: 26 patients with Class I malocclusion, and G2: 23 patients with Class II malocclusion, selected for orthodontic treatment. Evaluation of the condyle morphology and position was performed by the same previously calibrated examiner using cone-beam computed tomography (CBCT) images of the subjects. The CBCT scans were analyzed by means of a 3D program (Dolphin 11.5, Dolphin Imaging \& Management Solutions, Chatsworth, CA, USA), with a $25 \%$ level of sensitivity. The images obtained from the coronal slices were employed for the condyle morphology analysis, which classified the condyle form as rounded, as flat or convex, and as triangular or angled. The sagittal slices were used to classify further the condyles as concentric and displaced anteriorly or posteriorly. A clinical examination was also performed, including TMJ and muscle palpation. The kappa test was used to evaluate investigator calibration; the Chi-square and paired t-tests were used for analysis. The convex and anteriorly positioned condyles were found most frequently, regardless of the type of malocclusion. No association was observed between the groups regarding condylar characteristics.
\end{abstract}

Keywords: Mandibular Condyle; Temporomandibular Joint; Malocclusion.

\section{Introduction}

The temporomandibular joint (TMJ) is one of the most complex joints in the body and its harmonious functioning is very important to maintain a normal masticatory system. The morphologic alterations and the asymmetrical position of the TMJ structures may be influenced by different factors, such as dental absence, abrasion, premature contacts, parafunction, unilateral crossbite and dentoskeletal asymmetries. ${ }^{1}$

The morphology of the TMJ varies among individuals, and one of the factors that could influence its shape concerns the differences in functional loads imposed on it. This is based on the intimate relationship between form and function, and justifies the assumed differences in condyle and mandibular fossa morphology among subjects with different types of malocclusion. ${ }^{2}$ However, the influence of the occlusion is not completely understood., ${ }^{1,3}$ 
Although there are studies showing how joint characteristics relate to facial morphology, ${ }^{2,4}$ data are sparse and most studies focus mainly on the position of the condyle in the mandibular fossa, without mentioning its morphology. ${ }^{2}$ Conversely, several studies have evaluated condylar concentricity on tomographic scans, by using both symptomatic and/or asymptomatic samples, ${ }^{5,6,7,8}$ normal occlusion, ${ }^{9}$ or different modalities of malocclusion. ${ }^{1,10,1,12,13}$ Despite the numerous studies, the condylar position in the population remains a controversial topic. Further investigation is required to understand the high prevalence of posteriorly positioned condyles in subjects with symptoms of temporomandibular joint disorder (TMD) ${ }_{1}^{14}$ considering the wide variation in condyle positioning observed in the population. Additionally, there are few data on how the anatomical architecture of the TMJ may predict a normal function or dysfunction, or even the progression of symptoms. ${ }^{15}$

In orthodontics, the condyle position may be of interest for two main reasons, its relation either to TMJ dysfunction or to different mandibular corpus positions, which could affect orthodontic diagnosis and treatment. ${ }^{16}$

Another important issue during patient treatment planning concerns changing the nonconcentric position of the condyles or leaving them unchanged, especially when the treatment involves orthodontic/prosthetic and surgical approaches that could potentially lead to changes in the condyle position. Prognosis-related issues in cases of changing the condyle position due to orthodontic and surgical procedures, and in cases of condyle fracture, still remain unsolved. ${ }^{17}$

Another issue of discussion has been the best method of evaluating the morphology and positioning of the condyles. Some authors ${ }^{5}$ have demonstrated the precision of computed tomographic (CT) images to evaluate the joint spaces, as compared with transcranial x-rays. Moreover, cone-beam computed tomographic (CBCT) scans are considered the most appropriate images to evaluate the anatomic structures of patients for best diagnosis and treatment planning. 18,19

Considering that a malocclusion is a factor that could influence TMJ variation, the purpose of this study was to evaluate condylar morphology and concentricity in patients with Angle Class I and II malocclusion, using CBCT scans.

\section{Methodology}

This study was approved by the Research Ethics Committee of Universidade do Norte do Paraná UNOPAR, protocol number Pt/0088/11. During the screening process, patients and parents/guardians were fully informed of both the objectives of the study and all the clinical procedures, and could participate if they so wished. All participants or parents/guardians signed an informed consent form.

The study sample comprised 49 patients of both genders, aged 11-35 years (mean age, 16.40 years), selected from the patient files of UNOPAR. The sample was divided into 2 groups: G1, 26 Class I subjects; and G2, 23 Class II, division 1 subjects, with a bilateral distal molar relationship equal to or greater than one-half cusp width.

Complete permanent dentition or a maximum of two missing teeth in different quadrants, excluding the third molars, was deemed as inclusion criteria. The patients had no history of previous orthodontic or TMD treatment. The malocclusion classification was based on plaster models according to Angle criteria.

Evaluation of the condylar morphology and position was performed by the same previously calibrated examiner, using CBCT images of the subjects. The images were obtained with i-CAT tomography (Imaging Sciences International, Hatfield, USA). The scanning protocol was $120 \mathrm{kV}, 36.9 \mathrm{~mA}$, $13 \times 23 \mathrm{~cm}$ field of view, and 0.4-mm voxel, with patients in a natural head position. The images generated were exported to the Dolphin ${ }^{\mathrm{TM}} 11.5$ program (Dolphin Imaging \& Management Solutions, Chatsworth, USA) in Digital Imaging Communication in Medicine (DICOM) format.

Initially, the head orientation images were standardized. Observed from a front view, the horizontal plane was aligned with the orbits. The skull was repositioned according to the Frankfort horizontal plane. After this procedure, a sagittal reconstruction of the TMJ was obtained (Figure 1), and the central point of the condyle was marked to reconstruct the images of the sagittal and coronal TMJ (Figure 2). The classification of the condylar 
morphology was performed on a coronal slice, based on that proposed by Kinzinger et al., ${ }^{10}$ which defines condylar forms as rounded (A), flat or convex (B), and triangular or angled (C), as shown in Figure 3.

Condylar concentricity was measured on the most centered sagittal slice, based on the formula proposed by Pullinger and Hollender, ${ }^{20}$ as shown below.

$$
\frac{\mathrm{P}-\mathrm{A}}{\mathrm{P}+\mathrm{A}} \times 100(\%)
$$

The narrowest anterior $(\mathrm{A})$ and posterior $(\mathrm{P})$ articular spaces were calculated as shown in Figure 4. The concentric condyle in the articular fossa was indicated by a zero result, whereas a negative value indicated a posterior location and a positive value indicated an anterior location.

Clinical examinations were performed by a previously calibrated examiner. The presence of joint pain was detected during TMJ palpation performed bilaterally in the TMJ lateral and posterior aspects.

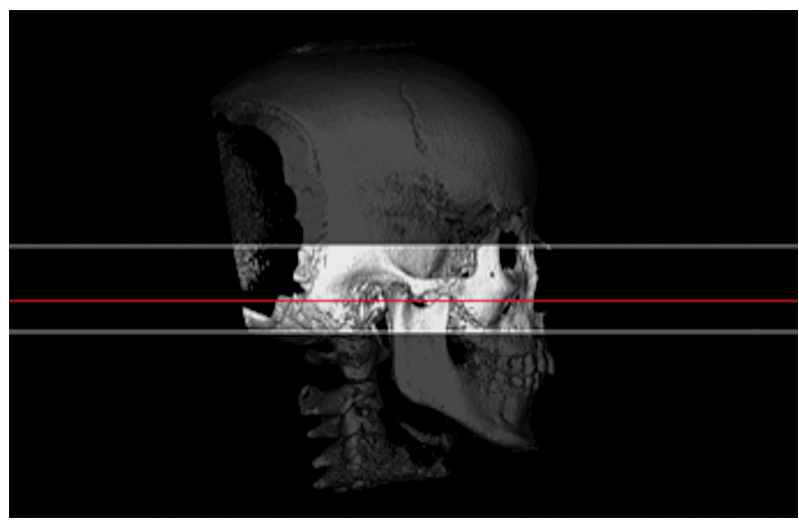

Figure 1. Sagittal view of the TMJ to perform the axial cuts.
The masticatory muscle examination comprised the palpation of the masseter and temporalis muscle.

\section{Statistical Analysis}

Statistical analysis was performed using GraphPad Prism 5.0 (GraphPad Software, San Diego, USA), BioStat 5.0 (Instituto Mamirauá, Tefé, Brazil) and G Power 3.0 (UCLA Institute for Digital Research and Education, Los Angeles, USA). A confidence interval of $95 \%$ and a significance level of $5 \%(p<0.05)$ were adopted for all the tests. After performing the Shapiro-Wilk normality test, the quantitative data were described by the mean and standard deviation of the parameters and by the absolute (n) and relative frequency (\%) of the qualitative data.

In order to avoid interexaminer error, a single investigator performed the measurements and the kappa test was used to evaluate investigator calibration in determining condyle morphology and concentricity.

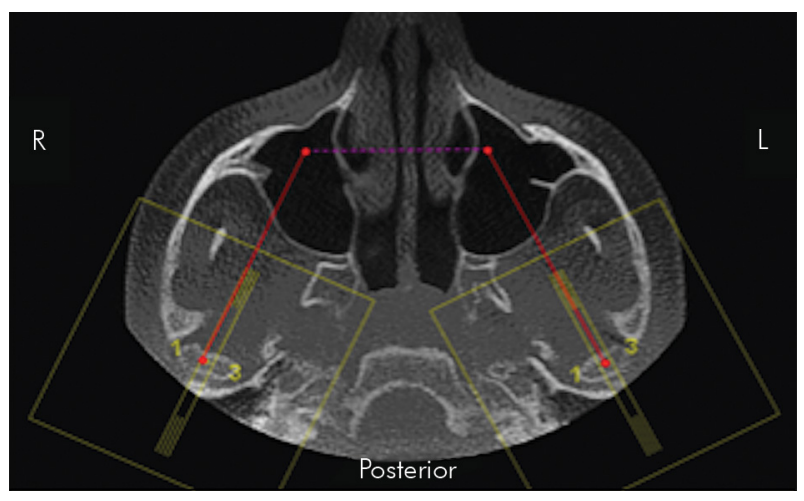

Figure 2. Axial view of the central condyle point to reproduce the sagittal and coronal TMJ slices.
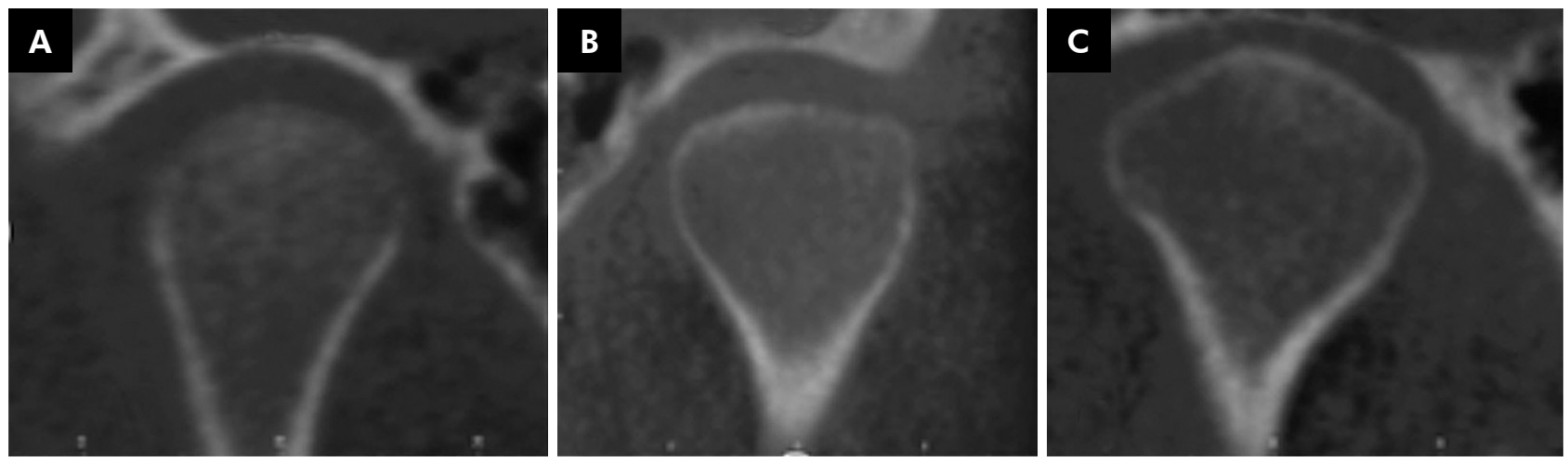

Figure 3. Coronal cuts for classification of condylar morphology: (A) Round, (B) convex (C) Angulated (Kinzinger et al. ${ }^{10}$ ). 


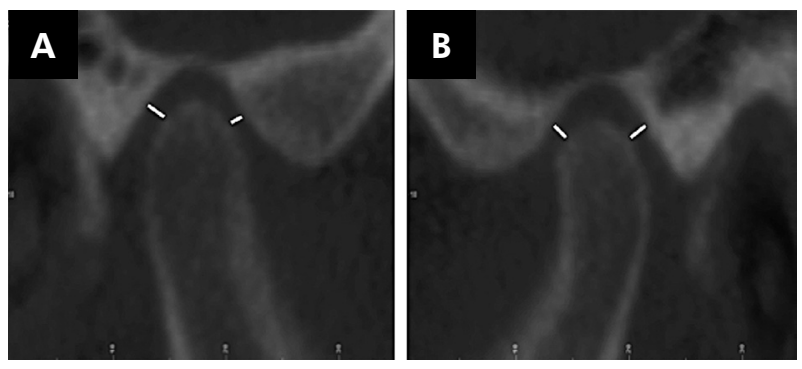

Figure 4. Sagittal cuts for measurement of the smallest joint spaces (anterior and posterior) to evaluate condyle concentricity: (A) Right condyle, (B) Left condyle.

The Chi-square test was applied for comparison of morphology and condylar concentricity between the groups, and the paired t-test, for comparison between the anterior and posterior joint spaces between right and left side for the two groups.

\section{Results}

A pilot study for examiner calibration was conducted in order to evaluate the condylar morphology and concentricity. The kappa coefficient was 0.68 for condyle concentricity and 0.84 for condylar morphology.

There was no statistically significant intergroup difference in age $(t=-0.11 ; p=0.90)$. The age range of G1 was 11-35.6 years (mean, $16.25 \pm 5.6$ years) and that of G2 was 10.9-31.5 years (mean, $16.4 \pm 6.0$ years). Both groups showed a similar gender distribution (Chi-square $=0.64 ; \mathrm{p}=0.61$ ). G1 comprised 8 male (30.77\%) and 18 female (69.23\%) patients, and G2, 10 male (41.67\%) and 14 female (58.33\%) patients. Thus, it was assumed that the groups were matched for gender and age.

Considering the condylar morphology, no association was found regarding the type of malocclusion (Chi-square test with Yates correction $=3.34 ; \mathrm{p}=0.18)($ Table 1$)$.
The measurement of the articular spaces was similar for the right and left sides, and for both the anterior and posterior TMJ in G1. Similar data were observed in G2, except for the posterior articular space, which showed a statistically significant difference in values $(p=0.007)$ between the two sides. These data are presented in Table 2. Moreover, no difference was observed regarding condylar concentricity between the two groups (Chi-square test with Yates correction $=4.84 ; \mathrm{p}=0.08)$ (Table 3).

In relation to the clinical examination, no difference was detected between TMJ tenderness and malocclusion (Chi-square test 0.79; $\mathrm{p}=0.54$, Table 4). Muscle tenderness to palpation was not associated with malocclusion type (Chi-square test $=2.26 ; p=0.22$, Table 5).

\section{Discussion}

The understanding of articular characteristics related to malocclusions may have clinical implications that are important for diagnosis and orthodontic treatment plans, ${ }^{19,21}$ which may change the condyle fossa relationship.

According to the results of this study, the condylar shape found was: G1, convex (57.7\%), round $(34.61 \%)$, and angulated $(7.69 \%)$, and G2, convex (75\%), round (20.83\%), and angulated $(4.17 \%)$, with no significant intergroup differences (Table 1). These numbers are in accordance with those of Kinzinger et al., ${ }^{10}$ in regard to condyle morphology being convex (55\%), round ( $25 \%)$, and angulated $(20 \%)$ in Class II patients, based on coronal magnetic resonance (MR) images. Katzavrias et al. ${ }^{21}$ found predominantly oval (60.4\%) and rounded (29.2\%) condyles in sagittal slices. Likewise, Karlo et al. ${ }^{22}$ found rounded condylar forms in children, also observed in sagittal slices. Solberg et al. ${ }^{23}$ found predominantly rounded $(66 \%)$, followed by flattened

Table 1. Comparison of condylar morphology between groups (Chi-square test with Yates correction, $p>0.05)$.

\begin{tabular}{|c|c|c|c|c|c|}
\hline & \multicolumn{3}{|c|}{ Condylar morphology } & \multirow{2}{*}{ Total (\%) } & \multirow{2}{*}{$\mathrm{p}$} \\
\hline & Convex (\%) & Angulated (\%) & Round (\%) & & \\
\hline Group 1 & $30(57.70)$ & $04(7.69)$ & $18(34.61)$ & $52(100.00)$ & \multirow{2}{*}{$0.18 \mathrm{~ns}$} \\
\hline Group 2 & $36(75.00)$ & $02(4.17)$ & $10(20.83)$ & $48(100.00)$ & \\
\hline
\end{tabular}

ns: non-significant difference. 
Table 2. Comparison of anterior and posterior joint space, mean $(M)$, standard deviation (SD) and $p$ value $(p)$ between the two groups, in both joints (paired t-test).

\begin{tabular}{ccccc}
\hline & \multicolumn{4}{c}{ Joint space } \\
\cline { 2 - 5 } & $\begin{array}{c}\text { Anterior } \\
(\mathrm{M} \pm \mathrm{SD})\end{array}$ & $\mathrm{p}$ & $\begin{array}{c}\text { Posterior } \\
(\mathrm{M} \pm \mathrm{SD})\end{array}$ & $\mathrm{p}$ \\
\hline Group 1 & & & & \\
Right side & $1.65 \pm 0.45$ & $0.96 \mathrm{~ns}$ & $2.04 \pm 0.69$ & $0.45 \mathrm{~ns}$ \\
Left side & $1.64 \pm 0.56$ & & $1.97 \pm 0.67$ & \\
Group 2 & & & & \\
Right side & $2.00 \pm 0.57$ & $0.47 \mathrm{~ns}$ & $2.00 \pm 0.81$ & $0.007^{*}$ \\
Left side & $2.10 \pm 0.86$ & & $2.33 \pm 0.83$ & \\
\hline
\end{tabular}

ns: non-significant difference.

* Statistically significant difference $(p<0.05)$.

(17\%), and angular (17\%) forms, in individuals of the same age, but the authors did not consider malocclusion in their study.

The controversy regarding the results cited may be justified by the difficulty in finding the best imaging method and suitable cuts for evaluating the morphology of the mandibular condyle. It is believed that the basic morphology of the condyle is established early in life, but changes during the individual's lifetime, according to the functional load. ${ }^{24}$ Perhaps the most important avenue of investigation would be to determine whether different malocclusions might indeed generate functional overload. Analyzing the influence of Class I, II, and III malocclusions on the mandibular fossa, Burley ${ }^{25}$ emphasized that the occlusal contacts in patients with malocclusions produce no functional stimulation that may alter the contour of the mandibular fossa.

Condylar concentricity was another parameter evaluated in this study. The anterior condyle position was prevalent in both groups. In G1, 73\% of the condyles were anterior, $25 \%$ were posterior, and only $2 \%$ were concentric, whereas in G2, 52\% of the condyles were anterior, $45 \%$ were posterior, and $2 \%$ were concentric.
The anterior and posterior articular spaces were similar for the right and left joints. G1 presented an average of $1.6 \pm 0.5 \mathrm{~mm}$ for the anterior articular spaces, and $2.0 \pm 0.6 \mathrm{~mm}$ for the posterior articular spaces, on both sides (Table 2). Rodrigues et al. ${ }^{12}$ also observed the anterior condyle displacement in a Class I sample, but with minor differences in the values of anterior (average of $1.3 \mathrm{~mm}$ ) and posterior (average of $1.7 \mathrm{~mm}$ ) articular spaces.

Similar data were observed for $\mathrm{G} 2$, with $2.0 \pm 0.5 \mathrm{~mm}$ and $2.1 \pm 0.8 \mathrm{~mm}$ for the anterior spaces, on the left and right sides, respectively. Regarding the posterior articular spaces, there was little statistically significant difference between the right $(2.1 \pm 0.8 \mathrm{~mm})$ and left $(2.3 \pm 0.8 \mathrm{~mm}$ ) sides (Table 2$)$. Kikuchi et al. ${ }^{26}$ found similar values for anterior (mean, $1.8 \mathrm{~mm}$ ) and posterior (mean, $2.29 \mathrm{~mm}$ ) articular spaces, in a sample of adolescents.

Anterior condylar displacement was also observed in several other studies, both in samples with Class $\mathrm{I}^{12}$ and Class $\mathrm{II}^{7,11,12,27}$ malocclusions, and in patients with normal occlusion, ${ }^{9}$ as well as in samples where the type of malocclusion was not considered. ${ }^{6}$

In contrast, some studies ${ }^{10,21}$ that also evaluated the condylar concentricity in Class II patients showed posteriorly positioned condyles; the former study ${ }^{10}$ was based on MR images. Although not statistically different, our results for G2 showed $45.83 \%$ of the condyles posteriorly positioned, whereas only $25 \%$ of the Class I patients presented this condition (Table 3). On the other hand, another study with Class II patients reported concentric condyles. ${ }^{2}$

As shown in the literature, a posteriorly aligned condyle observed in Class II division 2 subjects, unlike Class I or Class II division 1 patients, may occur due to distinct muscle characteristics. These subjects may present anteriorly positioned mastication muscles, which result in significant differences with respect to

Table 3. Comparison of condylar position between the groups (Chi-square test with Yates correction, $p>0.05$ ).

\begin{tabular}{|c|c|c|c|c|c|}
\hline & \multicolumn{3}{|c|}{ Condylar position } & \multirow{2}{*}{ Total (\%) } & \multirow{2}{*}{$\mathrm{p}$} \\
\hline & Anterior (\%) & Posterior (\%) & Concentric (\%) & & \\
\hline Group 1 & $38(73.07)$ & $13(25.00)$ & 01 (1.93) & $52(100.00)$ & \multirow{2}{*}{$0.08 \mathrm{~ns}$} \\
\hline Group 2 & 25 (52.09) & $22(45.83)$ & $01(2.08)$ & 48 (100.00) & \\
\hline
\end{tabular}

ns: non-significant difference. 
Table 4. Association of TMJ tenderness to palpation between the two groups (Chi-square test, $p>0.05)$.

\begin{tabular}{|c|c|c|c|c|}
\hline \multirow{2}{*}{ Groups } & \multicolumn{2}{|c|}{ TMJ tenderness to palpation } & \multirow{2}{*}{ Total (\%) } & \multirow{2}{*}{$\mathrm{p}$} \\
\hline & Absent (\%) & Present (\%) & & \\
\hline G1 & $13(50.00)$ & $13(50.00)$ & $26(100.00)$ & \multirow{2}{*}{$0.54 \mathrm{~ns}$} \\
\hline G2 & 09 (39.14) & $14(60.86)$ & $23(100.00)$ & \\
\hline
\end{tabular}

ns: non-significant difference.

the mechanical occlusal forces and their magnitude. ${ }^{4}$ Therefore, it follows that the muscle overload on the TMJ in Class II division 2 patients differs from that of patients with other dentofacial morphologies. ${ }^{28}$ Bearing in mind that TMJ morphology depends to some extent on its load, Class II division 2 patients must have specific morphological characteristics. ${ }^{2}$

During palpation procedures, $55.10 \%$ of the sample presented at least one TMJ tender site: G1- $50 \%$ and G2- $60.86 \%$ (Table 4). It is important to highlight that similar findings have been observed regardless of the type of malocclusion. This value is smaller than the $22.5 \%$ found in a similar Class I and II sample. ${ }^{29}$ Some differences are expected due to the variation in palpation techniques and pressure; this makes comparisons very unreliable.

Regarding muscle tenderness to palpation, $40.81 \%$ of the study sample had at least two tender sites (Table 5). Another study found a lower value $(26 \%)$ in Class I and II malocclusion patients, but this could be justified, because only one tender site was considered. ${ }^{29}$

\section{References}

1. Rodrigues AF, Fraga MR, Vitral RWF. Computed tomography evaluation of the temporomandibular joint in Class II Division 1 and Class III malocclusion patients: condylar symmetry and condyle-fossa relationship. Am J Orthod Dentofacial Orthop. 2009;136(2):199-206. doi:10.1016/j.ajodo.2007.07.033

2. Katsavrias EG. Morphology of the temporomandibular joint in subjects with Class II Division 2 malocclusions. Am J Orthod Dentofacial Orthop. 2006;129(4):470-8. doi:10.1016/j.ajodo.2005.01.018

3. Barrera-Mora JM, Espinar EE, Abalos LC, Llamas CJM, Ballesteros EJ, Solano RE, Rocabado M,et al. The relationship between malocclusion, benign joint hypermobility
Table 5. Association of muscle tenderness to palpation between the two groups (Chi-square test, $p>0.05$ ).

\begin{tabular}{|c|c|c|c|c|}
\hline \multirow{2}{*}{ Groups } & \multicolumn{2}{|c|}{ Muscle tenderness to palpation } & \multirow{2}{*}{ Total (\%) } & \multirow{2}{*}{$\mathrm{p}$} \\
\hline & Absent (\%) & Present (\%) & & \\
\hline G1 & $13(50.00)$ & $13(50.00)$ & $26(100.00)$ & \multirow{2}{*}{$0.22 \mathrm{~ns}$} \\
\hline G2 & $16(69.57)$ & $07(30.43)$ & $23(100.00)$ & \\
\hline
\end{tabular}

ns: non-significant difference.

Although the clinical evaluation results showed a high number of nonconcentric condyles, this fact may not influence TMJ clinical signs. The few number of concentric condyles with reduced anterior articular spaces found in our study seems to be a common finding in different types of malocclusion patients.,12,21 These findings are relevant because patients with anteriorly displaced condyles do not require a different orthodontic approach. This clinical implication is important, since it has been reported that a more posterior relative position of the condyle in the mandibular fossa could be one of the reasons for anterior disc displacement, which frequently results in TMJ sounds. ${ }^{30}$

\section{Conclusions}

The convex condyle shape was the most prevalent in this study and Class I and II patients seem to present similar condyle morphology.

Regarding the condyle position, anterior displacement was more prevalent regardless of the type of malocclusion.

syndrome, condylar position and TMD symptoms. J Cranio. 2012;30(2):121-30. doi:10.1179/crn.2012.018

4. Kurusu A, Horiuchi M, Soma K. Relationship between occlusal force and mandibular condyle morphology. Evaluated by limited cone-beam computed tomography. Angle Orthod. 2009;79(6):1063-9. doi:10.2319/120908-620R.1

5. Pullinger AG, Hollender L, Solberg WK, Petersson A. A tomografic study of mandibular condyle position in an asymptomatic population. J Prosthet Dent. 1985;53(5):706-13.

6. Ikeda K, Kawamura A. Assessment of optimal condylar position with limited cone-beam computed tomography. Am J Orthod Dentofacial Orthop. 2009;135(4):495-501. doi:10.1016/j.ajodo.2007.05.021 
7. Pullinger AG, Solberg WK, Hollender L, Petersson A. Relationship of mandibular condylar positon to dental occlusion factors in an asymptomatic population. Am J Orthod Dentofacial Orthop. 1987;91(3):200-206. doi:10.1016/0889-5406(87)90447-1

8. Bonilla-Aragon H, Tallents RT, Katzberg RW, YrkanidesS, Moss ME. Condyle position as a predictor of temporomandibular joint internal derangement. J Prosthet Dent. 1999;82(2):205-8. doi:10.1016/S0022-3913(99)70157-5

9. Vitral RW, Campos MJS, Rodrigues AF, Fraga MR. Temporomandibular joint and normal occlusion: Is there anything singular about it? A computed tomographic evaluation. Am J Orthod Dentofacial Orthop. 2011;140(1):1824. doi:10.1016/j.ajodo.2009.07.030

10. Kinzinger G, Kober C, Diedrich P. Topography and morphology of the mandibular condyle during fixed functional orthopedic treatment - a magnetic resonance imaging study. J Orofac Orthop. 2007;68(2):124-47. doi:10.1007/s00056-007-0650-0

11. Krisjane Z, Urtane I, Krumina G, Zepa K. Three-dimensional evaluation of TMJ parameters in Class II and Class III patients. Stomatologija. 2009;11(1):3236.

12. Rodrigues AF, Fraga MR, Vitral RWF. Computed tomography evaluation of the temporomandibular joint in Class I malocclusion patients: condylar symmetry and condyle-fossa relationship. Am J Orthod Dentofacial Orthop. 2009;136(2):192-8. doi:10.1016/j.ajodo.2007.07.032.

13. Vitral RW, Telles CS. Computed tomography evaluation of temporomandibular joint alterations in Class II Division 1 subdivision patients: condylar symmetry. Am J Orthod Dentofacial Orthop. 2002;121(4):369-75. doi:10.1067/mod.2002.121664

14. Pullinger AG, Solberg WK, Hollender L, Guichet D. Tomographic analysis of mandibular condyle position in diagnostic subgroups of temporomandibular disorders. J Prosthet Dent. 1986;55(6):723-9.

15. Okeson JP. Critical commentary 1: Evaluation of the research diagnostic criteria for temporomandibular disorders for the recognition of an anterior disc displacement with reduction. J Orofac Pain. 2009;23(4):312-5; author reply 323-4.

16. Williamson EH, Evans DL, Barton WA, Williams BH. The effect of bite plane use on terminal hinge axis location. Angle Orthod. 1977;47(1):25-33.

17. Pullinger AG, Seligman DA, John MT, Harkins S. Multifactorial modeling of temporomandibular anatomic and orthopedic relationships in normal versus undifferentiated disk displacement joints. J Prosthet Dent. 2002 Mar;87(3):289-97. doi:10.1067/mpr.2002.121741.
18. Mah JK, Huang JC, Choo H. Practical applications of cone-beam computed tomography in orthodontics. J Am Dent Assoc. 2010;141 Suppl 3:7S-13S.

19. Hodges RJ, Atchison KA, White SC. Impact of cone-beam computed tomography on orthodontic diagnosis and treatment planning. Am J Orthod Dentofacial Orthop. 2013;143(5):665-74. doi:10.1016/j.ajodo.2012.12.011

20. Pullinger A, Hollender L. Variation condyle-fossa relationships according to different methods of evaluation in tomograms. Oral Surg Oral Med Oral Pathol. 1986;62(6):719-27.

21. Katsavrias EG, Halazonetis DJ. Condyle and fossa shape in Class II and Class III skeletal patterns: a morphometric tomographic study. Am J Orthod Dentofacial Orthop. 2005;128(3):337-46. doi:10.1016/j.ajodo.2004.05.024

22. Karlo CA, Stolzmann P, Habernig S, Muller L, Saurenmann T, Kellenberger CJ. Size, shape and age-related changes of the mandibular condyle during childhood. Eur Radiol. 2010;20(10):2512-7. doi:10.1007/s00330-010-1828-1

23. Solberg WK, Hansson TL, Nordstrom B. The temporomandibular joint in young adults at autopsy: a morphologic classification and evaluation. J Oral Reabil. 1985;12(4):303-321.

24. Cimasoni G. Histopathology of the temporomandibular joint following bilateral extractions of molars in the rat. A preliminary report. Oral Surg Oral Med Oral Pathol. 1963;16:613-21.

25. Burley M. An examination of the relation between the radiographic appearance of the temporomandibular joint and some features of the occlusion. Br Dent J. 1961;110:195-200.

26. Kikuchi K, Takeuchi S, Tanaka E, Shibaguchi T, Tanne K. Association between condylar position, joint morphology and craniofacial morphology in orthodontic patients without temporomandibular joint disorders. J Oral Rehabil. 2003;30(11):1070-5. doi:10.1046/j.1365-2842.2003.01194.x

27. Uzel A, Özyürek Y, Öztunç H, Condyle position in Class II Division 1 malocclusion patients: correlation between MPI records and CBCT images. J World Fed Orthod. 2013;2(2):65-70. doi:10.1016/j.ejwf.2013.03.002

28. O’Ryan F, Epker BN. Temporomandibular joint function and morphology observations on the spectra of normalcy. Oral Surg Oral Med Oral Pathol. 1984;58(3):212-219.

29. Conti A, Freitas M, Conti P, Henriques J, Janson G. Relationship between signs and symptoms of temporomandibular disorders and orthodontic treatment: a cross-sectional study. Angle Orthod. 2003;73(4):411-7.

30. Kanavakis G, Mehta N. The role of occlusal curvatures and maxillary arch dimensions in patients with signs and symptoms of temporomandibular disorders. Angle Orthod. 2014;84(1):96-101. doi:10.2319/111312-870.1 